\title{
DISTRIBUIÇÃO DE ESCHERICHIA COLI NOS ÓRGÃOS DO SISTEMA MONONUCLEAR FAGOCITÁRIO APÓS ESPLENECTOMIA TOTAL ISOLADA OU COMBINADA COM AUTO-IMPLANTE ESPLÊNICO EM RATO
}

\author{
DISTRIBUTION OF ESCHERICHIA COLI IN MONONUCLEAR PHAGOCYTIC \\ SYSTEM ORGANS AFTER TOTAL SPLENECTOMY ISOLATED OR COMBINED \\ WITH SPLENIC AUTOTRANSPLANTATION IN RAT
}

\author{
Ruy Garcia Marques, TCBC-RJ ${ }^{1}$ \\ Andy Petroianu, TCBC-MG ${ }^{2}$
}

\begin{abstract}
RESUMO: Objetivo: O auto-implante esplênico parece constituir a única alternativa para preservação de tecido esplênico, após esplenectomia total. O objetivo deste trabalho foi analisar a depuração de Escherichia coli pelos órgãos do sistema mononuclear fagocitário (SMF) após esplenectomia total e auto-implante esplênico.Método: Utilizou-se um modelo experimental com ratos Wistar jovens e adultos, de ambos os sexos, submetidos a esplenectomia total e auto-implante esplênico. O método de avaliação foi a inoculação intravenosa de suspensão de Escherichia coli marcada com tecnécio-99m. Analisou-se a captação desta bactéria pelos órgãos do SMF e o remanescente bacteriano na corrente sangüínea. Resultados: Dentro de cada grupo, não foi encontrado diferença entre animais jovens e adultos no que se refere à captação de bactérias pelos órgãos do SMF. Na comparação entre os grupos verificou-se que o percentual médio de captação pelo baço e pelo fígado de animais do Grupo-Controle foi maior que o dos auto-implantes. Embora a captação de bactérias pelo baço de animais do Grupo-Controle tenha sido maior que o dos auto-implantes esplênicos, o remanescente bacteriano no sangue não foi diferente. Animais submetidos a esplenectomia total isolada apresentam maior remanescente de bactérias na corrente sangüínea que animais do GrupoControle ou do grupo submetido a esplenectomia total combinada com auto-implante esplênico. Conclusão: Nossos resultados indicam que o auto-implante esplênico é eficaz na depuração de bactérias, em rato, mediante a fagocitose por seus macrófagos, e não interfere na função de remoção bacteriana do fígado e do pulmão.
\end{abstract}

Descritores: Baço; Sepse; Esplenectomia; Fagocitose; Escherichia coli; Ratos wistar.

\section{INTRODUÇÃO}

Em 1952, King e Shumacker Jr. relataram complicações infecciosas graves após a realização de esplenectomias em cinco crianças com idade inferior a seis meses, duas evoluindo para óbito. ${ }^{1}$ Esse trabalho é o marco da literatura para a comprovação da associação entre esplenectomia e sepse. Contudo, inicialmente, julgou-se que o risco seria restrito a crianças. Diamond, em 1969, chamou a atenção para o

1. Professor Adjunto do Departamento de Cirurgia Geral da Faculdade de Ciências Médicas - UERJ; Coordenador do Laboratório de Cirurgia Experimental - FCM - UERJ; Mestre em Cirurgia Gastroenterológica - UFF; Doutor em Técnica Operatória e Cirurgia Experimental - UFMG.

2. Professor Titular do Departamento de Cirurgia da Faculdade de Medicina - UFMG; Docente-Livre em Técnica Operatória e Cirurgia Experimental da Escola Paulista de Medicina - UNIFESP; Docente-Livre em Gastroenterologia Cirúrgica da Faculdade de Medicina de Ribeirão Preto - USP; Doutor em Fisiologia e Farmacologia - UFMG; Pesquisador IA do CNPq. 
que denominou de infecção fulminante pósesplenectomia (IFPE), uma entidade clínica distinta de outras sepses ou bacteremias presentes em indivíduos com baço preservado, alertando para os riscos da asplenia. ${ }^{2}$ Em 1973, Singer mostrou que o risco de IFPE era muito maior que o imaginado previamente. Enfatizou que a sepse, poderia surgir em qualquer época após a cirurgia, tanto em adultos quanto em crianças, e salientou que seu risco independia da indicação para a esplenectomia. ${ }^{3}$

A partir desses trabalhos, diversas alternativas para preservar a função esplênica passaram a ser desenvolvidas, principalmente em pacientes com lesão esplênica oriunda de trauma abdominal. Dentre estas, encontram-se: tratamento conservador nãooperatório, ligadura ou embolizações arteriais, coagulação com LASER ou eletrocoagulações, aplicação de agentes hemostáticos tópicos, esplenorrafias (com ou sem a utilização de redes sintéticas) e esplenectomias parciais (quando puder preservar-se o pedículo esplênico) ou subtotais (com preservação apenas dos vasos esplenogástricos, nos casos em que o pedículo vascular tiver que ser ligado). A retirada completa do baço passou a ser aceita somente para os casos em que há uma lesão extensa do órgão e de seu pedículo, cirurgicamente incontrolável, ou para doenças diretamente relacionadas à função esplênica alterada. ${ }^{4-12}$

Em 1978, Pearson et al. verificaram a presença de função esplênica em crianças com tecido esplênico espontaneamente implantado (esplenose), após esplenectomias por trauma. ${ }^{13}$

Com base nos achados clinicopatológicos dos implantes esplênicos espontâneos, o implante esplênico autógeno heterotópico passou a ser considerado como uma opção na tentativa de preservar as funções do baço, nos casos em que fosse inevitável a sua retirada. ${ }^{4,14-17}$

O auto-implante esplênico parece constituir a única alternativa para preservação de tecido esplênico após esplenectomia total. O objetivo deste trabalho foi analisar a depuração sangüínea da Escherichia coli nos órgãos do sistema mononuclear fagocitário (SMF) após esplenectomia total isolada ou combinada com auto-implante esplênico.

\section{MÉTODO}

Este trabalho foi aprovado pelo Conselho de Ética em Pesquisa Animal do Laboratório de Cirurgia
Experimental da Faculdade de Ciências Médicas da Universidade do Estado do Rio de Janeiro. Todos os procedimentos seguiram, rigorosamente, a regulamentação existente sobre experimentação com animais. ${ }^{18-19}$

Foram utilizados 90 ratos Wistar albinos, de ambos os sexos. Os animais foram divididos em três grupos: I - controle - sem manipulação cirúrgica; II - submetidos a esplenectomia total isolada; e III submetidos a esplenectomia total combinada com auto-implante esplênico. Cada um destes grupos foi subdividido em dois subgrupos: A - 48 ratos jovens, com peso variando entre $100 \mathrm{~g}$ e $150 \mathrm{~g}$ (grupo I cinco machos e nove fêmeas; grupo II - oito machos e sete fêmeas; grupo III - cinco machos e 14 fêmeas); e B - 42 ratos adultos, com peso variando entre $250 \mathrm{~g}$ e $300 \mathrm{~g}$ (grupo I - quatro machos e dez fêmeas; grupo II - seis machos e nove fêmeas; grupo III - oito machos e cinco fêmeas). Os animais foram colocados em gaiolas apropriadas, máximo de cinco por gaiola, e receberam ração própria para ratos e água ad libitum.

Após jejum de seis horas, os animais foram submetidos a anestesia inalatória com halotano, tricotomia abdominal, anti-sepsia com iodopovidine e colocação de campos operatórios. Através de laparotomia mediana supra-umbilical, procedeu-se à esplenectomia total. No grupo submetido a auto-implante esplênico, o baço, após pesagem, foi seccionado transversalmente em cinco fatias, cada uma com cerca de $2 \mathrm{~mm}$ de espessura. As secções esplênicas foram implantadas no omento maior, mediante sutura contínua, com fio de ácido poliglicólico 4-0. Os pontos foram dados alternadamente, no omento e no tecido esplênico, para que houvesse interposição de tecido omental entre as fatias esplênicas. A laparorrafia foi realizada com sutura contínua, em dois planos (plano peritonioaponeurótico e pele), com fio de ácido poliglicólico 3-0.

Utilizou-se a linhagem de Escherichia coli AB1157, marcada com tecnécio-99m (Tc-99m), sob a forma de pertecnetato de sódio $\left(\mathrm{Tc} \mathrm{O}_{4} \mathrm{Na}\right)$, a partir de técnica previamente descrita. ${ }^{20,21}$ Obteve-se percentual de marcação de bactérias superior a $95 \%$ e concentração bacteriana correspondente a $10^{8}$ unidades formadoras de colônias (UFC).

Após 16 semanas do início do experimento, sob anestesia inalatória com halotano, realizou-se tricotomia cervical e abdominal nos animais, e antisepsia com iodopovidine. Através de cervicotomia transversa direita, dissecou-se a veia jugular interna, 
e inoculou-se a suspensão contendo Escherichia coli marcada com Tc-99m. Depois de 20 minutos da inoculação, os animais foram mortos, com dose letal de halotano, e submetidos a toracolaparotomia mediana. Seccionou-se a veia cava caudal, provocando sangramento intra-abdominal que resultou na formação de um coágulo sangüíneo. Procedeu-se à retirada do fígado, pulmão e baço ou auto-implante esplênico, assim como do coágulo sangüíneo, que foram pesados e colocados em tubos apropriados para contagem radioativa em cintilômetro para raios gama.

Para efeito de cálculo, utilizou-se um padrão de dose, contendo o mesmo volume e a mesma atividade da suspensão de Escherichia coli marcada com Tc-99m inoculada nos animais. A contagem do padrão foi considerada como $100 \%$ de radioatividade inoculada nos animais. O percentual de captação de cada amostra foi calculado pela fórmula:

$$
\% \text { de captação }=\frac{\text { cpm da amostra }}{\text { cpm padrão }} \times 100
$$

Levando-se em consideração a massa de fígado, pulmão, baço ou auto-implante e do coágulo sangüíneo, o percentual de captação por grama de tecido, foi calculado pela fórmula:

$\%$ de captação $/ \mathrm{g}=\frac{\% \text { de captação de cada tecido }}{\text { massa de cada } \operatorname{amostra}(\mathrm{g})}$

O percentual de captação de cada órgão (massa total) foi calculado pela fórmula:

$\%$ de captação do órgão =

$\%$ de captação / g x massa total do órgão (g)

Durante as laparotomias para retirada dos órgãos, em dez ratos jovens e dez adultos, colheu-se $1,0 \mathrm{ml}$ de sangue da veia cava caudal, que foi colocado em tubo de ensaio e deixado em repouso por 24 horas. Esses tubos foram centrifugados, para total individualização de soro e coágulo. Os coágulos foram pesados, observando-se que, em média, cada mililitro de sangue resultou em 0,49065 g de coágulo, em ambos os subgrupos. Como um rato de $250 \mathrm{~g}$ tem $16 \mathrm{ml}$ de sangue, equivale dizer que o volume total de sangue circulante nesse mesmo rato resulta em 7,8504 g de coágulo. ${ }^{22}$ Mediante a massa de coágulo, calculou-se o percentual de captação de todo o sangue de cada animal.

Normalizou-se a distribuição de bactérias captadas, assumindo-se que fígado, pulmão e baço ou auto-implante, acrescidos do sangue (bactérias remanescentes na corrente sanguínea), respondem pela totalidade da captação (100\%).

As análises estatísticas visaram a comparação do comportamento dos grupos e subgrupos de animais, no que tange à captação de bactérias marcadas com Tc-99m pelo fígado, pulmão e baço ou auto-implante, bem como do remanescente bacteriano na corrente sangüínea. $O$ teste $t$ de Student foi aplicado a pares de grupos e subgrupos de animais. Focalizando as variações na captação de bactérias no fígado, pulmão, baço ou auto-implante, e sangue, utilizou-se ainda modelos de regressão linear múltipla. Nesses modelos explorou-se os efeitos independentes do peso final, faixa etária e sexo dos animais, bem como da esplenectomia total e do auto-implante esplênico, comparados ao grupo controle. Também considerou-se a possibilidade de o sexo dos animais modificar o efeito do peso final pela inclusão de um termo de interação dessas variáveis. O nível de significância considerado foi de $5 \% .^{23}$

\section{RESULTADOS}

A tabela 1 mostra a análise descritiva dos percentuais de captação de bactérias. A análise comparativa entre animais jovens e adultos, dentro de cada grupo, mostrou não haver diferença nos percentuais de captação de bactérias pelos órgãos do SMF. As únicas exceções foram observadas na comparação de animais jovens e adultos submetidos a auto-implante esplênico, no que se refere à captação pelo fígado e pulmão: o percentual de captação hepática em animais jovens foi maior que em animais adultos $(\mathrm{p}=0,0081)$ e, em contraposição, a captação pulmonar em animais adultos foi maior que em animais jovens $(\mathrm{p}=0,0072)$ (Tabela 2).

A comparação entre os grupos, considerando animais jovens ou adultos, separadamente, é apresentada na Tabela 3. No que tange ao remanescente bacteriano no sangue, ele foi maior no grupo esplenectomizado. Por outro lado, não houve diferença entre a bacteremia dos animais do Grupo-Controle e a dos submetidos a auto-implante. $\mathrm{O}$ percentual médio de captação pelo baço e pelo fígado de animais 
Tabela 1 - Análise descritiva dos percentuais de captação de Escherichia coli, por animais jovens e adultos, nos grupos controle (I), com esplenectomia total isolada (II) e esplenectomia total combinada com auto-implante esplênico (III).

\begin{tabular}{ccrrrr|rrrr}
\hline Grupos & \multicolumn{5}{c|}{ Animais jovens } & \multicolumn{4}{c}{ Animais adultos } \\
\hline \multirow{6}{*}{ I } & Média & 77,2551 & 17,6436 & 2,5126 & 2,5887 & 78,4926 & 16,4909 & 2,2901 & 2,7264 \\
& DP & 4,6719 & 3,8343 & 0,7999 & 1,5226 & 3,8810 & 4,2204 & 0,8773 & 0,9827 \\
II & Média & 77,3743 & 18,3786 & --- & 4,2471 & 75,9407 & 19,0428 & -- & 5,0165 \\
& DP & 5,3058 & 4,6277 & --- & 2,1774 & 3,2519 & 3,4521 & - & 1,7609 \\
III & Média & 79,0740 & 16,5384 & 0,9427 & 3,4449 & 75,2450 & 20,5706 & 1,2474 & 2,9370 \\
& DP & 3,7779 & 3,6441 & 0,7596 & 1,7574 & 3,7139 & 4,2213 & 0,7284 & 1,2906 \\
\hline
\end{tabular}

DP - Desvio padrão

do Grupo-Controle foi maior que o dos auto-implantes, tanto em animais jovens $(\mathrm{p}<0,0001)$ quanto adultos $(\mathrm{p}=0,0026)$. Entretanto, a captação pelo pulmão foi maior no grupo com auto-implante esplênico do que no Grupo-Controle.

Nos modelos de regressão linear múltipla, para animais jovens e adultos, separadamente, observou-se que, nos adultos, o grupo com auto-implante apresentou captação maior pelo pulmão $(\mathrm{p}=0,0114)$ e menor pelo fígado $(\mathrm{p}=0,0176)$. Também observou-se que fêmeas jovens apresentaram menor captação pelo pulmão que fêmeas adultas $(\mathrm{p}=0,0218)$. A captação de bactérias pelo auto-implante foi menor que a do baço, tanto ao considerarem-se todos os ratos $(\mathrm{p}<0,0001)$, quanto ao considerarem-se somente ratos jovens ( $\mathrm{p}<0,0001)$ ou adultos $(\mathrm{p}=0,0620)$.

\section{DISCUSSÃO}

O auto-implante esplênico em animais jovens parece propiciar melhor regeneração morfológica e maior recuperação da atividade funcional que em adultos. ${ }^{24-26}$ Essa foi a razão para realizar-se o mesmo experimento com animais em duas faixas etárias, jovem e adulta. Quanto mais jovem o animal, maior a sua capacidade de regeneração tecidual, o que pode explicar a melhor recuperação funcional do implante esplênico autógeno nesses animais. ${ }^{25,26}$

Utilizamos a linhagem selvagem de Escherichia coli $\mathrm{AB} 1157$, por fazer parte da flora intestinal normal, em humanos, e por ser responsável por cerca de $12 \%$ dos casos de IFPE. ${ }^{3}$ Essas bactérias gram-negativas predominam nas infecções em pacientes esplenectomizados idosos e debilitados por

Tabela 2 - Comparação entre subgrupos de animais (jovens - A vs. adultos - B), em um mesmo grupo, pelo teste t de Student-valores de p.

\begin{tabular}{cllcc}
\hline Subgrupos & Fígado & Pulmão & $\begin{array}{c}\text { Baço ou } \\
\text { auto-implante }\end{array}$ & Sangue \\
\hline IA - IB & 0,4527 & 0,4562 & 0,4895 & 0,7783 \\
IIA - IIB & 0,3799 & 0,6593 & --- & 0,2964 \\
IIIA - IIIB & $0,0081^{*}$ & $0,0072^{*}$ & 0,2662 & 0,3811 \\
\hline
\end{tabular}

\footnotetext{
* Diferença significativa

I - Grupo-Controle

II - Esplenectomia total isolada

III - Esplenectomia total combinada com auto-implante esplênico
} 
Tabela 3 - Comparação entre subgrupos de animais (jovens - A vs. adultos - B), nos três grupos, pelo teste $t$ de Student ( valores de p).

\begin{tabular}{lllll}
\hline Subgrupos & Fígado & Pulmão & $\begin{array}{c}\text { Baço ou } \\
\text { auto-implante }\end{array}$ & Sangue \\
\hline IA - IIA & 0,9494 & 0,6465 & -- & $0,0257^{*}$ \\
IA - IIIA & 0,2255 & 0,4060 & $0,0000^{*}$ & 0,1539 \\
IIA - IIIA & 1,2834 & 0,2034 & -- & 0,2429 \\
IB - IIB & 0,0649 & 0,0851 & -- & $0,0002^{*}$ \\
IB - IIIB & $0,0359^{*}$ & $0,0189^{*}$ & $0,0026^{*}$ & 0,6360 \\
IIB - IIIB & 0,6015 & 0,3017 & --- & $0,0016^{*}$ \\
\hline
\end{tabular}

* Diferença significativa

I - Grupo-Controle

II - Esplenectomia total isolada

III - Esplenectomia total combinada com auto-implante esplênico

doenças crônicas. Para estudo da resposta à inoculação de bactérias gram-negativas, a via intravenosa parece mimetizar melhor a situação clínica, visto que a sepse devido a essas bactérias é proveniente do sistema digestório e não do respiratório.

Já foi mostrado que a presença de tecido esplênico remanescente funcionante in situ propicia melhor depuração sangüínea de Escherichia coli, em ratos e coelhos. ${ }^{11,27}$ Contudo, ainda não havia sido avaliada a depuração sangüínea dessas bactérias gram-negativas, não-encapsuladas, pelos órgãos do sistema mononuclear fagocitário (SMF), em ratos submetidos a esplenectomia total isolada ou combinada com auto-implante esplênico.

De acordo com a literatura, o baço é responsável por $25 \%$ a $30 \%$ da depuração sangüínea realizada pelo SMF. ${ }^{8,26,27}$ Tais estudos, realizados em sua maioria com substâncias coloidais, não foram comprovados pelos resultados do presente trabalho, conduzido com bactérias. A participação dos órgãos do SMF na fagocitose de bactérias difere da verificada com substâncias coloidais. O fígado é o órgão com maior capacidade de depuração sangüínea, tanto de colóide quanto de bactérias. Em seguida, o baço remove mais substâncias coloidais, enquanto o pulmão é órgão que mais depura bactérias do sangue.

Poder-se-ia especular que o maior índice fagocitário pulmonar se deva ao fato de a bactéria ter sido inoculada pela veia jugular interna, permitindo, assim, que o primeiro contato com os principais órgãos do SMF ocorra no pulmão. Dessa forma, os macrófagos pulmonares exerceriam maior ação, por entrarem em contato com um grande inóculo bacteriano que ainda não passou pelo fígado e pelo baço. Não encontramos dados na literatura que mostrem o baço como primeiro órgão de contato com a bactéria. Para que tal ocorra, a bactéria deve ser inoculada na aorta torácica, permitindo que alcance, simultaneamente, baço e fígado.

A captação de bactérias pelo baço de animais do Grupo-Controle foi maior que o dos autoimplantes esplênicos, tanto para ratos jovens quanto para adultos, embora nesses últimos essa diferença seja menor. Da mesma forma, na comparação entre animais esplenectomizados e aqueles submetidos a auto-implante esplênico, em ambos os sexos, ratos adultos esplenectomizados apresentaram maior remanescente bacteriano no sangue, enquanto com os jovens não ocorreu diferença. Ainda que possam refletir características específicas da amostra analisada, esses achados sugerem que, em animais adultos, com maior massa esplênica regenerada, a atividade fagocitária seja maior que em jovens.

No presente estudo, animais com implante esplênico autógeno apresentaram melhor função fagocitária dos órgãos do SMF que os esplenectomizados, com diminuição do remanescente bacteriano no sangue, comprovando melhor função depuratória.

Diversos trabalhos têm mostrado que o autoimplante esplênico é um procedimento simples e que não se associa a grandes complicações. Sua utiliza- 
ção possibilita a recuperação de diversas funções do baço e pode levar a possíveis benefícios em humanos. ${ }^{4,14,15}$ Nossos achados sugerem que o auto-im- plante esplênico preserva a função fagocitária do baço e propicia proteção contra a sepse por Escherichia coli, em rato.

\begin{abstract}
Background: Splenic autotransplantation seems to be the only alternative for the preservation of splenic tissue, after total splenectomy. The present study was perfomed to analyze Escherichia coli depuration by mononuclear phagocytic system organs after total splenectomy and splenic autotransplantation. Methods: We utilized an experimental model including young and adult Wistar rats, of both sexes, submitted to total splenectomy and splenic autotransplantation. The evaluation method was intravenous inoculation of a suspension of Escherichia coli labeled with technetium-99m. We analyzed bacteria uptake by mononuclear phagocytic system organs and bacteria remnant in the bloodstream. Results: There was no difference between young and adult animals in bacteria uptake by mononuclear phagocytic system organs. The mean percentage uptake by spleen and liver of animals in the control group was higher than that observed for animals with splenic implants. However, bacteria uptake in the lung was higher in the splenic implant group than in the control group. Although spleen bacteria uptake in the control group animals has been higher than that of animals in the splenic implant group, the remnant bacteria in the bloodstream was similar. Animals submitted to isolated total splenectomy showed higher bacteria remnant in the bloodstream than animals of the control group or the group submitted to total splenectomy combined with splenic autotransplantation. Conclusion: Our results indicate that autogenous splenic implant is efficacious in bacteria depuration in rats, by means of their macrophages phagocytosis. In addition, it does not modify bacteria removal function of liver and lung.
\end{abstract}

Key Words: Spleen; Sepsis; Splenectomy; Phagocytosis; Escherichia coli; Rats, wistar.

\section{REFERÊNCIAS}

1. King H, Shumacker HB Jr - Splenic studies. I. Susceptibility to infection after splenectomy performed in infancy. Ann Surg, 1952, 136: 239-242.

2. Diamond LK - Splenectomy in childhood and the hazard of overwhelming infection. Pediatrics, 1969, 43(5): 886-889.

3. Singer DB - Postsplenectomy sepsis. Perspect Pediatr Pathol, 1973, 1: 285-311.

4. Millikan JS, Moore EE, Moore GE, et al. - Alternatives to splenectomy in adults after trauma. Repair, partial, resection, and reimplantation of splenic tissue. Am J Surg, 1982, 144(6): 711-716.

5. Resende V, Petroianu A - Subtotal splenectomy for treatment of severe splenic injuries. J Trauma, 1998, 44(5): 933-935.

6. Pachter HL, Grau J - The current status of splenic preservation. Adv Surg, 2000, 34: 137-174.

7. Petroianu A - Subtotal splenectomy in Gaucher's disease. Eur J Surg, 1996, 162: (6): 511-513.
8. Petroianu A, Simal CJR, Barbosa AJA - Splenic macrophage phagocytic function after subtotal splenectomy in the dog. Med Sci Res, 1992, 20: 127128.

9. Farag A, Shoukry A, Nasr SE - A new option for splenic preservation in normal sized spleen based on preserved histology and phagocytic function of the upper pole using upper short gastric vessels. Am J Surg, 1994, 168(3): 257-261.

10. Petroianu A, Barbosa AJA - Quantitative studies on macrophage phagocytosis in whole spleen and in the remnant of subtotal splenectomy. Med Sci Res, 1991, 19: 373-375.

11. Silva RG. Fagocitose da Escherichia coli pelo sistema mononuclear fagocitário, após esplenectomias subtotal, parcial e total, em rato. Dissertação (Doutorado em Técnica Cirúrgica e Cirurgia Experimental). Belo Horizonte. Universidade Federal de Minas Gerais, 2000.

12. Sumaraju V, Smith LG, Smith SM - Infectious complications in asplenic hosts. Infect Dis Clin North Am, 2001, 15(2): 551-565. 
13. Pearson HA, Johnston D, Smith KA, et al. - The bornagain spleen. Return of splenic function after splenectomy of trauma. N Engl J Med, 1978, 298(25): 1389-1392.

14. Resende V, Petroianu A - Estudo funcional tardio do auto-implante esplênico após trauma complexo do baço humano. Rev Col Bras Cir, 2001, 28(3): 165-170.

15. Petroianu A, Vidigal FM, Costa VC, et al. - Splenic autotransplantation in Gaucher's disease. Dig Surg, 2000, 17(2): 181-183.

16. Patel J, Williams JS, Shmigel B, et al. - Preservation of splenic function by autotransplantation of traumatized spleen in man. Surgery, 1981, 90(4):683-688.

17. Corazza GR, Tarozzi C, Vaira D, et al. - Return of splenic function after splenectomy: how much tissue is needed? Br Med J, 1984, 289(6449): 861-864.

18. Hoff $\mathrm{C}-$ Sounding board. Immoral and moral uses of animals. N Engl J Med, 1980, 302(2): 115-118.

19. Petroianu A. Pesquisa experimental. In Petroianu A (ed) - Ética Moral e Deontologia Médica. $1^{a}$ Edição. Rio de Janeiro, Guanabara Koogan, 2000, pp. 185190.

20. Bernardo-Filho M, Pereira JAA, Boasquevisque EM Labeling of Klebsiella pneumoniae with technetium99m - A preliminary communication. Rev Microbiol, 1986, 17: 188-193.

21. Diniz SO, Resende BM, Nunan EA, et al. ${ }^{99 \mathrm{~m}}$ Technetium labelled Escherichia coli. Appl Radiat Isot, 1999, 51(1): 33-36.
22. Diehl KH, Hull R, Morton D, et al. - A good practice guide to the administration of substances and removal of blood, including routes and volumes. J Appl Toxicol, 2001, 21(1): 15-23.

23. Altman DG, Gardner MJ - Means and their differences. In Altman DG, Machin D, Bryant TN, Gardner MJ (eds.) - Statistics with confidence. $2^{\text {nd }}$ edition. Bristol. British Medical Journal Books, 2000, pp. 28-35.

24. Tavassoli M, Ratzan RJ, Crosby WH - Studies on regeneration of heterotopic splenic autotransplants. Blood, 1973, 41(5): 701-709.

25. Iinuma H, Okinaga K, Sato S, et al. - Optimal site and amount of splenic tissue for autotransplantation. J Surg Res, 1992, 53(2): 109-116.

26. Malangoni MA, Dawes LG, Droege EA, et al. - Splenic phagocytic function after partial splenectomy and splenic autotransplantation. Arch Surg, 1985, 120(3): 275-278.

27. Chaudry IH, Tubata Y, Schleck S, et al. - Effect of splenectomy on reticuloendothelial function and survival following sepsis. J Trauma, 1980, 20 (8):649656.

Endereço para correspondência:

Ruy Garcia Marques

Rua Clóvis Salgado 280/104

Recreio - Rio de Janeiro - RJ

CEP 22795-230

E-mail: rmarques@uerj.br 